\title{
A Cross Sectional Study of Knowledge and attitudes levels about Polio Vaccination among selected sample of Technical Institute $\backslash$ AL-Suwaira staff members Jasim Mohammed Muhsin (Msc) ${ }^{1}$ and Ahmed Kadhim Jawad (Msc) $)^{2}$
}

\begin{abstract}
Background: The previous laboratory investigations confirmed local polio case was informed on $28^{\text {th }}$ January 2000 and another two wild polio cases were reported from Resafa $\backslash$ Baghdad province in 2014. The date of onset of these cases were February and April 2014 and both cases were connected to 2013 of Syria outbreak.

Objective:To evaluate the knowledge and attitudes levels towards polio vaccination among staff of Technical Institute - AL-Suwaira.

Patients and Methods: A study of cross-sectional design consisted of 170 a selected samples of Technical Institute \ AL-Suwaira staff members. Collected during January 2018. The knowledge and attitudes levels estimated by using typical design of selfadministered questionnaire. Descriptive statistics were used to explain the results.

Results: Over all, 170 participants reacted to the questionnaire by a response rate of $93.5 \%$. All respondents established a good knowledge and positive attitudes levels to poliovirus vaccination. Mean knowledge score (built on 11 knowledge questions) and mean attitude score (built on 10 attitudes statements) of participants about polio vaccine were $14.45 \pm 2.38$ and $26.5 \pm 4.5$ respectively. The mainstream of respondents agreed that all children should be taken the polio vaccine $(88.2 \%)$, and the sterility concerns that associated with polio vaccines (14.1\%). Television $(n=126,39 \%)$ and Internet $(n=66,21 \%)$ were the main social media sources that used by staff members to educate and modify themselves about polio vaccination. Knowledge defects were recognized in the management issues and how to dealing with vaccines $(45.9 \%)$, the incubation period of poliovirus infection (38.8\%) and the consequences of the poliovirus infection $(56.5 \%)$ on the victims.

Conclusion: Staff members of Technical Institute $\backslash$ AL-Suwaira showed a good knowledge and positive attitudes levels about polio vaccination. Even though the statistics are indicative of knowledge gaps of participants, further studies are needed to assess these levels for better education program against polio.
\end{abstract}

Keywords: Polio, Vaccination, Knowledge, Attitude.

Corresponding Author: jasim.muhsin99@gmail.com

Received: $3^{\text {th }}$ October 2018

Accepted: $4^{\text {th }}$ November 2018 https://doi.org/10.26505/DJM

${ }^{1}$ Health and Medical Technology College -Middle Technical University - Baghdad - Iraq.

${ }^{2}$ Technical Institute-Suwaira - Middle Technical University - Wasit - Iraq. 


\section{Introduction}

Polio (poliomyelitis) is communicable and highly contiguous viral disease caused by the poliovirus strains frequently called infantile paralysis or polio. Caused by three strains of poliovirus (PV) which are poliovirus (PV1), (PV2), and (PV3) differs by capsid protein and yield the same symptoms of disease which considered the PV1 is the most common serotype that is closely related to paralysis[1]. Any age group can infected by the polio, but children under five years of age has the affinity to get infection that effect onto the nervous system. Regularly, patients expose no symptoms, but about (1-200) infected children have paralysis and occasionally death. [1, 2]. There are two types of poliovirus infection which are: a minor disease does not the central nervous system (CNS) involvement, and a major type with the (CNS) involvement, which may be with paralytic type or non-paralytic type [2]. Poliovirus infection is asymptomatic in most individuals with normal immunity, the polio infection accompany with minor symptoms such as; include gastrointestinal disturbances upper respiratory tract infection (URT) and influenza-like illness [3]. Polio virus usually introduces to human body from the environment via fecal-oral transmission. Furthermore, and a direct contact (person to person) can cause polio [4]. The poliovirus infection its preventable diseases by using the polio vaccine; nevertheless, different dosage are needed in order to be effective [5]. There are two kinds of vaccines are used to use against poliovirus infection. Both of them produce immunity against polio infection, capably prevent direct transmission of poliovirus infection. By Jonas Salk in the 1950s the first attempt of polio vaccine was developed [6,7].Vaccination boosters recommends for travelers and those who live in countries where polio is spread according to the Centers for Disease Control of US (CDC) and Prevention polio [8]. There is no specific treatment in 2016, there were 37 infected cases of wild strain of polio and 5 cases of vaccine-derived polio. In 2014 the polio infection was only spreading among people who are living in Nigeria, Afghanistan, and Pakistan [5]. Nigeria in 2015 stopped the spread of wild poliovirus infection but it again activated and reoccurred in 2016 with new cases [9, 10], the poliovirus transmitted (from Syria to Iraq in the Middle East zone) and (from Pakistan to Afghanistan of central Asia) also its spread (from Cameroon to Equatorial Guinea, and from Equatorial Guinea to Brazil) [4]. Iraq is affected by an outbreak of poliovirus infection from virus of Pakistani origin. Since 2000, Iraq has not had a case of poliovirus wild infection. The last laboratoryidentified original polio case was stated on 28 January, 2000. And there were two wild polio cases in 2014 were reported from Baghdad - Resafa province. Dates of onset of the cases were months of February and April 2014. Surprisingly, both cases were linked to Syria outbreak of 2013[11, 12].

The current study presented to evaluate the knowledge and attitudes levels among sample among staff members in Technical 
A Cross Sectional Study of Knowledge and attitudes levels about Polio Vaccination among selected

Institute AL-Suwaira about Polio Vaccination.

\section{Patients and Methods}

\section{Participants and Study design}

A cross-sectional descriptive study was

[13 14], administrated at January 2018 among sample of staff in Technical Institute AL-Suwaira which include; technician, administrative, lecturer and others were considered adequate to participate into this study. Data collection and explanation to the participants were the responsibility of authors, a self-organized questionnaire which was given into our participants to fulfil their responses after tested it carefully and reviewing all its contents including; validity and consistency, by sending the initial draft to three professionals for their views on the simplicity of statements, the relativity to the main subject, and the significance of the contents. Questionnaire format consist of 4 parts. 1st; Socio-economic Characteristics of participants such as; Sex, age interval, qualification, occupation, marital status and residence. 2nd; the knowledge evaluation based on 11 questions regarding to causes, signs and symptoms, mode of transmission, diagnosis, controlling, incubation period of viral infection and its management in order to evaluated the knowledge of staff in Technical Institute AL-Suwaira about polio vaccination. 3rd; the attitudes assessment based on 10 statements with four responses scale for each one. The fourth part was explored and determined the source of information of participants about polio vaccination.

\section{Statistical analysis}

Participant's responses were analysed by using SPSS v.20 program. Demographic criteria as frequencies and percentages expressed by using descriptive analysis. The knowledge level estimate by relative subject questions answered by of Yes/No as a participants response categories, $(0-10)$ was the knowledge scores intervals and the cutoff level of $\leq 1$ was expressed as the poor knowledge and $>1$ expressed as good knowledge of participants. Four point's scale of agreement was used to determine the responses of participants for attitudes statement. A score of (1) was given to agree, (2) to strongly agree, (3) to disagree and (4) to strongly disagree. Negative attitude score was $\leq 2$, while $>2$ scored as positive attitude of participants.

\section{Results}

A response rate of $93.5 \%$ are given from the total of 170 participants which responded to the questionnaire of our recent study. Most of participants were with age interval of 35 to 44 years $(\mathrm{n}=74,43.5 \%)$, males were $(\mathrm{n}=81$, 47.6) while females were $(n=89,52.4)$ and most of participants had diploma degree $(\mathrm{n}=$ $85,50.0 \%)$. Technicians $(\mathrm{n}=82,48.2 \%)$, lecturers $(\mathrm{n}=46,27.1 \%)$ and the major respondents in this study were administrative as $(\mathrm{n}=34,20.0 \%)$. The married respondents were $(\mathrm{n}=148,87.1 \%)$ which were higher than the single respondents by $(\mathrm{n}=20$, $11.8 \%)$. The numbers of respondents from rural areas $(n=66,38.8 \%)$ and urban areas were $(n=104,61.2 \%)$ Table(1). 
Table (1): The Socio-economic Characteristics of the respondents.

\begin{tabular}{|c|c|c|c|}
\hline \multicolumn{2}{|c|}{ Socio-economic Characteristics } & $\overline{\mathrm{NO}}$. & Percent (\%) \\
\hline \multirow{5}{*}{ Age Groups } & $<25$ & 12 & $7.1 \%$ \\
\hline & $(25-34)$ & 42 & $24.7 \%$ \\
\hline & $(35-44)$ & 74 & $43.5 \%$ \\
\hline & $\geq 45$ & 42 & $24.7 \%$ \\
\hline & $\overline{\text { Total }}$ & 170 & $100 \%$ \\
\hline \multirow{3}{*}{ Genders } & Male & 81 & $47.6 \%$ \\
\hline & Female & 89 & $52.4 \%$ \\
\hline & Total & 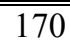 & $100 \%$ \\
\hline \multirow{7}{*}{ Qualifications } & Diploma & 85 & $50.0 \%$ \\
\hline & "High Diploma & 1 & $0.6 \%$ \\
\hline & $\overline{\text { Bachelors }}$ & 44 & $25.9 \%$ \\
\hline & Masters & 24 & $14.1 \%$ \\
\hline & Doctorate & 6 & $3.5 \%$ \\
\hline & Others & 10 & $5.9 \%$ \\
\hline & Total & 170 & $100 \%$ \\
\hline \multirow{5}{*}{ Occupation Status } & Technician & 82 & $48.2 \%$ \\
\hline & Administrative & 34 & $20 \%$ \\
\hline & Lecturer & 46 & $27.1 \%$ \\
\hline & Others & 8 & $4.7 \%$ \\
\hline & Total & 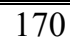 & $100 \%$ \\
\hline \multirow{4}{*}{ Marital Status } & Married & 148 & $87.1 \%$ \\
\hline & Unmarried & 20 & $11.8 \%$ \\
\hline & Others & 2 & $1.2 \%$ \\
\hline & Total & 170 & $100 \%$ \\
\hline \multirow{3}{*}{ Residence } & Rural & 66 & $38.8 \%$ \\
\hline & Urban & 104 & $61.2 \%$ \\
\hline & Total & 170 & $100 \%$ \\
\hline
\end{tabular}

Based on 11 questions to determine knowledge of respondents, with mean knowledge score $14.45 \pm 2.38$. Our sample, $100 \%(\mathrm{n}=170)$ participants showed good range of knowledge, $71.8 \%(n=122)$ of respondents correctly replied that the polio infection is a viral infection. High knowledge level about the role of immunization against of poliovirus infection $(\mathrm{n}=144,87.7 \%)$. Most of respondents had knowledge for which age group with tendency of polio infection $(n=140,82.4 \%)$. In contrast, $(n=$ 
$66,38.8 \%$ ) of respondents were with low knowledge about the incubation period of poliovirus infection. Likewise, $54.1 \%(\mathrm{n}=$ 92) respondents incorrectly replied regarding to that polio is curable. Furthermore, more than half of participants $56.5 \%(\mathrm{n}=96)$ wrongly responded that polio is incurable and with fatal outcomes Table (2).

Table (2): The Knowledge level of respondents towards polio vaccination.

\begin{tabular}{|l||c||c||}
\hline \multicolumn{1}{|c|}{ Questions } & $\begin{array}{c}\text { Correct answer } \\
(\%)\end{array}$ & $\begin{array}{c}\text { Incorrect answer } \\
(\%)\end{array}$ \\
\hline \hline Polio infection is a viral disease & $122(71.8)$ & $48(28.2)$ \\
\hline \hline $\begin{array}{l}\text { The affinity of Polio infection to the under 5 years of age and } \\
\text { it's also called infantile paralysis }\end{array}$ & $140(82.4)$ & $30(17.6)$ \\
\hline \hline $\begin{array}{l}\text { Incubation period 3-6 days of poliovirus infection } \\
\text { Immunization Absence against polio is a main risk factor of } \\
\text { poliovirus infection }\end{array}$ & $66(38.8)$ & $144(84.7)$ \\
\hline \hline $\begin{array}{l}\text { Traveling to outbreak areas with a polio is consider at risk factor } \\
\text { for children infection }\end{array}$ & $86(50.6)$ & $26(15.3)$ \\
\hline \hline Polio viral transmission by the fecal-oral or respiratory routes & $66(38.8)$ & $104(61.2)$ \\
\hline \hline Polio is curable & $78(45.9)$ & $92(54.1)$ \\
\hline \hline $\begin{array}{l}\text { To avoid viral transmission to people, patients should be } \\
\text { isolated till the diagnosis }\end{array}$ & $60(35.3)$ & $110(64.7)$ \\
\hline \hline $\begin{array}{l}\text { Swabs sample of respiratory is recommended for isolating polio } \\
\text { in suspected patients }\end{array}$ & $58(34.1)$ & $112(65.9)$ \\
\hline \hline $\begin{array}{l}\text { Immunization is the most active way of preventing and } \\
\text { controlling polio }\end{array}$ & $148(87.1)$ & $22(12.9)$ \\
\hline \hline Poliovirus infection is a fatal to patients & $74(43.5)$ & $96(56.5)$ \\
\hline \hline
\end{tabular}

Based on 10 attitude statements, the mean attitude score was $26.5 \pm 4.5$ of participants about polio vaccination. And, $67.1 \%(\mathrm{n}=$ 114) of respondents presented a positive attitudes. Most of participants $(\mathrm{n}=148$, $87.1 \%$ ) showed agreed or strongly responses that polio infection is a very severe and lifethreating illness. About of $50.6 \%(\mathrm{n}=86)$ of respondents assumed that all children must be vaccinated against polio, regarding to the storage of vaccine to save effectiveness, participants strongly agreed or agreed that polio vaccines by $91.8 \%(\mathrm{n}=156)$. Nevertheless, respondents not believed polio vaccines have sterility concerns by $50.6 \%$ (n $=86$ ). Contrary, respondents replied that polio vaccination course must be repeated by 42.4\% ( $\mathrm{n}=72)$. Moreover, about $(\mathrm{n}=128$, $75.3 \%$ ) which indicate more than a half of respondents stated their disagreement with the polio problems of its very severe in the region or their residence Table (3). 
Table (3): The Attitude levels of respondents towards polio vaccination.

\begin{tabular}{|c|c|c|c|c|}
\hline \multirow[t]{2}{*}{ Questions } & \multicolumn{4}{|c|}{ Participant's responses N (\%) } \\
\hline & Agree & "Strongly agree & Disagree & $\begin{array}{l}\text { Strongly } \\
\text { disagree }\end{array}$ \\
\hline Poliovirus infection is a very serious disease & $88(51.8)$ & $60(35.3)$ & $22(12.9)$ & $0(0)$ \\
\hline $\begin{array}{l}\text { Poliovirus infection have a very severe problem } \\
\text { in your region }\end{array}$ & $12(7.1)$ & $10(5.9)$ & $128(75.3)$ & $20(11.8)$ \\
\hline $\begin{array}{l}\text { Vaccination against polio are unable to reduce the } \\
\text { transmission of infection }\end{array}$ & $52(30.6)$ & $22(12.9)$ & $70(41.2)$ & $26(15.3)$ \\
\hline $\begin{array}{l}\text { To ovoid the harm and over dosage to children } \\
\text { the polio vaccination should not be repeated }\end{array}$ & $60(35.3)$ & $18(10.6)$ & $72(42.4)$ & $20(11.8)$ \\
\hline Storage of polio vaccines in order to be effective & $76(44.7)$ & $80(47.1)$ & $10(5.9)$ & $4(2.4)$ \\
\hline $\begin{array}{l}\text { Polio vaccines related to some of sterility } \\
\text { concerns }\end{array}$ & $34(20)$ & $24(14.1)$ & $86(50.6)$ & $26(15.3)$ \\
\hline $\begin{array}{l}\text { All children should be vaccinated against polio } \\
\text { infection }\end{array}$ & $64(37.6)$ & $86(50.6)$ & $12(7.1)$ & $8(4.7)$ \\
\hline $\begin{array}{l}\text { Communities should actively participate in } \\
\text { controlling and preventing poliovirus infection in } \\
\text { Iraq }\end{array}$ & $82(48.2)$ & $74(43.5)$ & $12(7.1)$ & $2(1.2)$ \\
\hline $\begin{array}{l}\text { Individuals infected with poliovirus infection are } \\
\text { less productive than non-disabled ones }\end{array}$ & $48(28.2)$ & $52(30.6)$ & $58(34.1)$ & $12(7.1)$ \\
\hline $\begin{array}{l}\text { After polio vaccination, many severe side effects } \\
\text { can be occurred to the patients. }\end{array}$ & $22(12.9)$ & $20(11.8)$ & $102(60)$ & $26(15.3)$ \\
\hline
\end{tabular}

Table (4) showed knowledge scores assessment that ranged from $0-10$, poor knowledge with cut off level of $\leq 1$ while $>1$ give good knowledge of participants. 156 $(91.8 \%)$ were with good knowledge, while 14 $(8.2 \%)$ of participants were with poor level of knowledge. The participant's responses over attitudes statement were estimated as score of $\leq 2$ as negative attitude, while $>2$ as positive attitude level. 114 (67.1\%) were with positive attitudes, while $56(32.9 \%)$ were with negative attitudes. 
Table (4): Knowledge levels assessment.

\begin{tabular}{|c|c|c||c|}
\hline \hline Levels & Mean of score & Frequency & $\%$ \\
\hline \hline Poor & $0.1-1$ & 14 & $8.2 \%$ \\
\hline \hline Good & $1.1-2$ & 156 & $91.8 \%$ \\
\hline \hline Total & $1-2$ & 170 & $100 \%$ \\
\hline \hline \multicolumn{3}{|c|}{ Attitude levels assessment } \\
\hline \hline Levels & Mean of score & Frequency & $\%$ \\
\hline \hline Negative & $0.1-2$ & 56 & $32.9 \%$ \\
\hline \hline Positive & $2.1-4$ & 114 & $67.1 \%$ \\
\hline \hline Total & $1-4$ & 170 & $100 \%$ \\
\hline \hline
\end{tabular}

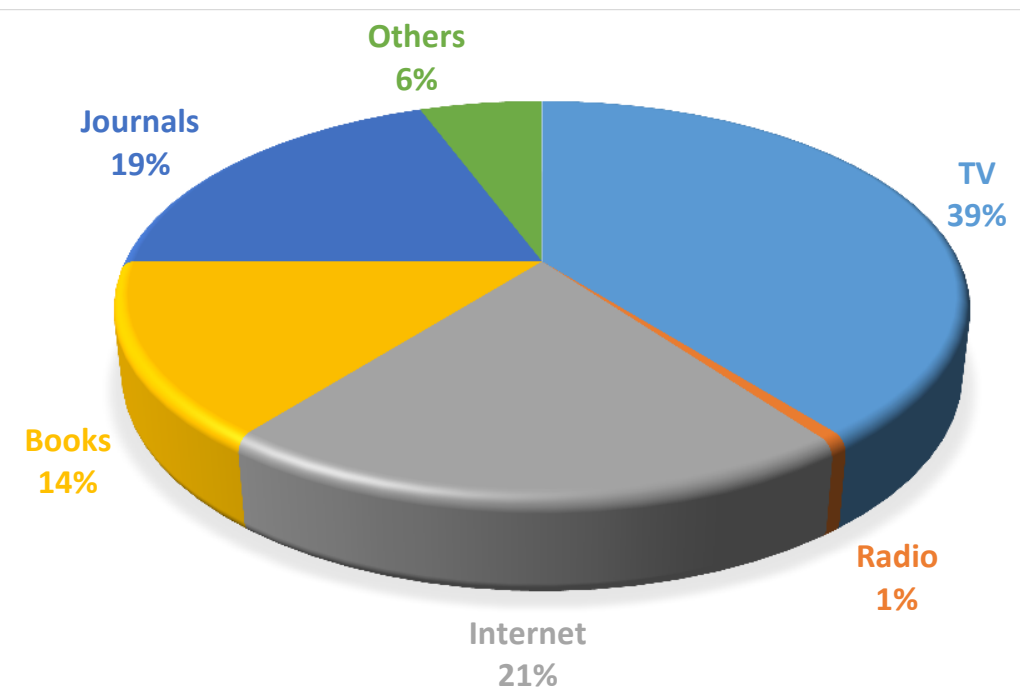

Figure (1): Information sources of participants about polio vaccination in Technical Institute $\backslash$ ALSuwaira.

Figure (1) showed the Television (39\%) and internet $(21 \%)$ were the main sources used by respondents to fulfil their educating level about polio vaccination, In addition the other sources which includes; posters or conferences, books, journals and Radio was the least source as $(1 \%)$. 


\section{Discussion}

The individuality of this research is that it established place where not much data is accessible. However, it is significant to remark that the consequences of this study have boundaries, although the study was conducted in Technical Institute \ ALSuwaira, the outcomes may not be generalized to other regions so it is useful to review a large sample size in different zones in order to clarify this issue. Even though of the limits was known, our results have significant consequences for the controlling and prevention of polio infection with more future exploration. The outcomes of this report could have important inferences for the expansion of future approaches for polio education programs and delivering of facts to the people generally and parents specifically to expand their knowledge and attitudes levels about poliovirus vaccination as they are an important members of our community, and taken a full community importance of caring and management of the families. Moreover, this report highlights the need for further researches in the future established in different areas such as hospitals or other educational centers to validate our recent outcomes.

Generally, participants showed good knowledge about polio vaccination. Some of them recognized the polio virus infection and significance of the immunizing of the age intervals that most vulnerable to the infection. Study in Pakistan as a survey mode stated insufficient knowledge among healthcare workers $(\mathrm{HCW})$ concerning immunization against polio virus [15]. The cause of this inconsistency could be the statistic that last Pakistani study was established from a long time where not enough data were available, after that the immunization campaigns activity had been exaggerated in Pakistan, which may effect on the knowledge of HCWs about polio vaccination positively[16 ]. The recent study also explored the criteria that need to elevate the levels among participants such as viral incubation period (61.2\%), mode of transmission $(61.2 \%)$, possibility to cure polio $(54.1 \%)$, diagnosis of disease $(64.7 \%)$, isolating of virus (65.9), and the possibility of death with polio (56.5\%).A study established in India determined that all of the respondents had knew about polio. Nevertheless, only 35 (10.9\%) respondents heard that the poliovirus is fecal-oral transmitted. Even though, 288 (90\%) respondents identified that polio is a preventable viral disease, $87(27.2 \%)$ were under the misunderstanding that it is curable infection [17].In addition the latter study agreed with our study that showed the Television was the primary tool of information about pulse polio immunization (PPI) programme among $60 \%$ of respondents while it was $39 \%$ in our recent study [17].

Regarding to the source of information, Social Media source is one of the significant and important tools to which youths of every population are mostly exposed, which consider a rich source of information that everyone can obtains a useful data. Due to 
A Cross Sectional Study of Knowledge and attitudes levels about Polio Vaccination among selected

sample of Technical Institute $\backslash$ AL-Suwaira staff members

this reason, they were more knowledgeable than older people $[16,18]$. A study reveals that participants of age less than 45 years have relatively good knowledge about polio and vaccination as compared to the participants older than 45 years. Population having low income, low literacy rate and living in rural areas would need to be educated [16, 19-21].

Nevertheless, a study showed a knowledge level only $60 \%$ of the participants knew about polio vaccination [22]. Analogous conclusions were stated by another study as $56 \%$ only knew about polio vaccination and only $63 \%$ of participants knew that it is preventable viral disease [23]. The variances between the above two studies may be due to the last studies were accomplished in a rural area and our study were done in urban area of residence but the sample selection were among educated levels. This could show that the knowledge level about polio vaccination varies regarding to the residency. Furthermore, in the study made by Singh et al $30.7 \%$ of participants supposed polio to be a curable viral disease [24].

The present study also explored the attitudes of Technical Institute $\backslash$ AL-Suwaira staff about polio vaccination. The outcomes were displayed positive attitudes towards polio vaccines storage. It has been stated on many studies that cold weather maintenance is vital element to save the polio vaccines effectiveness [25, 26, 27]. Contrary, the attitude levels of participants about polio vaccines administration were negative [27, 28]. The likely reason for this divergence could be the recent lack of awareness of polio educational program in certain areas of Iraq or any other country. However, it is important to notice many of them were with positive attitude towards participating in controlling program of polio virus infection [29]. The outcomes propose negative attitude levels of the participants about the polio activity and sterility concerns. These results of consist of multivariate analysis established with using different age, qualification, profession and experience [29].

Generally, the attitude of the participants was positive regarding to the polio vaccine effectiveness as compared to the study that was done in Peshawar and Quetta division [16]. Many revisions revealed the negative attitude of the participants towards quality and perpetuation of polio vaccines. As this is an issue in different areas of Pakistan. Different studies highlight the awareness about cold chain maintenance of polio vaccines $[16,30]$. But a study, showed the people of Abbottabad and Mansehra displayed a positive response towards quality of polio vaccines and its reliability [31]. Effectiveness and safety of the polio vaccines were closely related to its maintenance due to the problem of electricity load shedding as other studies also notifying this issue [16]. This study revealed the contribution of a community in polio campaigns is directly connected to the education and awareness program of the people in Iraq. Medical and health care providers play a main role in building awareness among people in different areas. 
A Cross Sectional Study of Knowledge and attitudes levels about Polio Vaccination among selected

sample of Technical Institute $\backslash$ AL-Suwaira staff members

Internet and Social media and other operative approaches at government level aid in generating awareness among people. Educational level is significantly related with the awareness and it can also be mentioned by other studies [32, 33, and 34]. In the specific study beside qualification, gender, occupation, income and residence were also connected with the attitude towards polio and its vaccination. Among main information sources, media is much significantly associated with attitude questions.

According to the vaccine dosage and side effects of it, our study, rather than knowledge, participants' awareness about polio and its vaccination was also reviewed. Mainstream of the participants think that lack of knowledge among the people is the major reasons of non-immunization. But the studies and analysis says that lack of trust on health services, quality of polio vaccines and its side effects, poor maintenance of the polio vaccines produce self-doubt among the people are also the main reasons. People are frightened of taking over dosing of polio vaccines as oral drops (3-4) times per month. There is another problem which was revealed in one of the studies that was conducted in India [32, 35] that the repeated doses of the oral polio vaccine ( OPV ) in a single month lead to over dosage, considering it to be the major cause of polio outbreak in elderly. For child caring, mothers play central role in completing and effecting the immunization schedules of diverse life threatening diseases after giving birth [36,
37, and 38]. Awareness about dosage times of polio vaccines are very essential for health care workers (HCWs) as well as for mothers for the prevention of adversative effects of polio vaccines [39].

A study also shows a misunderstanding was known in $2.2 \%$ of participants [32] as they supposed that repeated vaccination cycles under pulse polio immunization (PPI) programme results in over dosage of vaccination and giving side effects. This was similar to the study finding, where 2.2 to $6.3 \%$ of respondents in several districts by fearing some of them to not give the vaccine their children due to the fear of over dose [35]. Consequently, the results customize the needing to interventions that obviously rise the knowledge level of participants in the above identified issues, like management of polio vaccines and the penalties of polio vaccination of life-threating issues maybe result in transmission of wrong information.

\section{Conclusions}

Generally, polio vaccination revealed a good knowledge and positive attitudes of participants toward it. Still, there is some criteria concerning of polio vaccines need some improvement of knowledge and attitudes, our outcomes may not be reflect a general view. Therefore, additional revisions need to validate the results of the current study.

\section{References}

[1]Ryan KJ, Ray CG, eds. (2004). "Enteroviruses". Sherris Medical Microbiology (4th ed.). McGraw Hill. pp. 535-7. 
[2]Banerjee K, Haldy WG, Andrus JK, Sarkar S, Fitzsimmons J, Abeykoon P. Poliomyelitis surveillance: the model used in India for polio eradication. Bull World Health Organ. 2000;78:321-9.

[3]Falconer M, Bollenbach E . "Late functional loss in nonparalytic polio". American Journal of Physical Medicine \& Rehabilitation 2000; 79 (1): 19-23.

[4]Hamborsky J, Kroger A, Wolfe C, eds. "Poliomyelitis", Epidemiology and Prevention of Vaccine-Preventable Diseases (The Pink Book) (13th ed.), Washington DC: Public Health Foundation, (chap. 18), 2015.

[5]Centre for Disease Prevention and Control .Progress toward poliomyelitis eradication Nigeria, January 2013-September (2014)/ 63(46); 1059-1063.

[6]Poliomyelitis Fact sheet N-114". WHO.int. October 2014. Retrieved 3 November 2014.

[7]Aylward R ."Eradicating polio: today's challenges and tomorrow's legacy". Annals of Tropical Medicine and Parasitology 2006; 100 (5-6): 401-13.

[8]"Global leaders support new six-year plan to deliver a polio-free world by 2018" http://www.who.int. 25 April 2013. Retrieved 4 November 2014.

[9]"Guidance to US Clinicians Regarding New WHO Polio Vaccination Requirements for Travel by Residents of and Long-term Visitors to Countries with Active Polio Transmission". CDC. 2 June 2014. Retrieved 4 June 2014.
[10]WHO Removes Nigeria from PolioEndemic List". www.who.int. Retrieved 28 September 2015.

[11]"Government of Nigeria reports 2 wild polio cases, first since July 2014". WHO. 11 August 2016. Retrieved 15 August 2016.

[12]WHO Iraq, http://www.emro.who.int/polio/countries/ira q.html.

[13]Schmidt, C.O.; T. Kohlmann. When to use the odds ratio or the relative risk? Int. J. Public Health, 2008, 53(3), 165-167.

[14]Lee, J. Odds ratio or relative risk for cross-sectional data? Int. J. Epidemiol., 1994, 23(1), 201-203.

[15]Ahmed SI, Baig L, Thaver IH, Siddiqui MI, Jafery SI, Javed A (2001) Knowledge, attitudes and practices of general practitioners in Karachi District Central about tetanus immunization in adults. J Pak MedAssoc. 51(10):367-9.

[16]Khan, M.U.; Ahmad, A.; Aqeel, T.; Salman, S.; Ibrahim, Q.; Idrees, J.; Khan, M.U. Knowledge, attitudes and perceptions towards polio immunization among residents of two highly affected regions of Pakistan. BMC public health, 2015, 15(1), 1.

[17]N Joseph, SH Subba, M Nelliyanil, SM Kotian, AC Haridath, Kishor N,5 S Attavar, Poornima P, DV Rane, Chaithali $\mathrm{H}$, and Husain J, A study of the knowledge and attitude towards pulse polio immunization in semi urban areas of South India, Australas Med J. 2011; 4(2): 81-86.

[18]Vance, K.; Howe, W.; Dellavalle, R.P. Social internet sites as a source of public 
A Cross Sectional Study of Knowledge and attitudes levels about Polio Vaccination among selected

health information. Dermatol. Clin., 2009, 27(2), 133-136.

[19]Fotso, J. Child health inequities in developing countries: differences across urban and rural areas. Int. J. Equity. Health, 2015, 5, 10.

[20]Jajoo, U.N; Chhabra, S.; Gupta, O.P.; Jain, A.P. Annual cluster (pulse) immunization experience in villages near Sevagram, India. J. Trop. Med. Hyg., 1985, 88(4), 277-280.

[21]Mansuri, F.A.; Baig, L.A. Assessment of immunization service in perspective of both the recipients and the providers: A reflection from focus group discussions. J. Ayub. Med. Coll. Abbottabad, 2003, 15(1), 14-18.

[22]Chincholikar SV, Prayag RD. Evaluation of PPI in rural area of Maharashtra. Indian J Pediatr. 2000;67(9):647-9.

[23]Misra P, Goswami A, Pandav CS. A study of the perception, communication and coverage of pulse polio immunization programme in a Delhi slum. Indian J Public Health. 2004;48(4):216-7.

[24]Singh MM, Bano Tanveer, Dabas Pratibha, Mehra Malti. Awareness about PPI among general population in Delhi. Indian $\mathbf{J}$ Med Sci. 2001;55(8):453-7.

[25]Yakum MN, Ateudjieu J, Walter EA, Watcho P (2015) Vaccine storage and cold chain monitoring in the North West region of Cameroon: a cross sectional study. BMC research notes 8:145 doi: 10.1186/s13104015-1109-9.

[26] 26. Owais A, Khowaja AR, Ali SA, Zaidi AK (2013) Pakistan's expanded programme on immunization: An overview in the context of polio eradication and strategies for improving coverage. Vaccine.31:3313-3319.

[27]Azira B, Norhayati MN, Norwati D (2013). Knowledge, Attitude and Adherence to Cold Chain among General Practitioners in Kelantan, Malaysia. Int J Colla Res Int Med Pub Heal. 5:157-67.

[28]Chhnang K (2002) Attitudes Towards Immunization in Cambodia: A Qualitative Study of Health Worker and Community Knowledge, Attitudes and Practices in.PATH and AIHI.JA Forder, PATH Consultant, July 12, 2002, Available.

[29]Nishtar S (2010) Pakistan, politics and polio. Bulletin of the World Health Organization 88:159-160.

[30]Shrivastava, A.; Gupta, N.; Upadhyay, P.; Puliyel, J. Caution needed in using oral polio vaccine beyond the cold chain: Vaccine vial monitors may be unreliable at high temperatures. Indian J. Med. Res., 2012, 135(4), 520.

[31]Humaira Saeed 1 , Saira Azhar1,2,*, Akash Syed 1 , Saliha Khalid 1 , Annum Bukhari 1 and Nidda Saeed1, Polio and its Vaccination: A Cross Sectional Study of Knowledge, Attitude and Perception of General Public in district Abbottabad and Mansehra, Khyber Pakhtunkhwa, Pakistan, Anti-Infective Agents, 2018, 16, 22-31.

[32]Joseph, N.; Subba, S.H.; Nelliyanil, M.; Kotian, S.M.; Haridath, A.C.A. Study of the knowledge and attitude towards pulse polio immunization in semi urban areas of South India. Australas. Med. J., 2011, 4(2), 81. 
[33]Chincholikar, S.; R. Prayag. Evaluation of pulse-polio immunisation in rural area of Maharashtra. Indian J. Pediatr., 2000, 67(9), 647-649.

[34]Rasania, S.K.; Sachdev, T.R. Pulse polio programme: An overview of parent's perception. J. Commun. Dis., 2000, 32(4), 275-283.

[35]Dobe, M.; Ray, S.K.; Biswas, R.; Mandal, A.; Meheta, P.; Baishya, A. C. Evaluation of pulse polio immunization in some districts of West Bengal \& Assam. Indian J. Public Health, 2003, 48(2), 88-95.

[36]Nisar, N.; M. Mirza,; Qadri, M.H. Knowledge, Attitude and Practices of mothers regarding immunization of one year old child at Mawatch Goth, Kemari Town, Karachi. Pak. J. Med. Sci., 2010, 26(1), 183186.

[37]Nisar, N.; M. Mirza,; Qadri, M.H. Knowledge, Attitude and Practices of mothers regarding immunization of one year old child at Mawatch Goth, Kemari Town, Karachi. Pak. J. Med. Sci., 2010, 26(1), 183186.

[38]Achappa, B. Knowledge, attitude and perceptions of mothers with children under five years of age about vaccination in Mangalore, India. Asian J. Med. Sci., 2014, 5(4), 52-57.

[39]Ahmad, I.; Yunusa, I.; Wudil, A.M.; Gidado, Z.M.; Sharif, A.A.; Kabara, H.T. Knowledge, Attitude, Perception and Beliefs of Parents/Care givers About Polio Immunization 2015. 